Article

\title{
Mapping and Explaining Media Quality: Insights from Switzerland's Multilingual Media System
}

\author{
Linards Udris ${ }^{1, *}$, Mark Eisenegger ${ }^{1}$, Daniel Vogler ${ }^{2}$, Jörg Schneider ${ }^{2}$ and Andrea Häuptli ${ }^{1}$ \\ ${ }^{1}$ Department of Communication and Media Research, University of Zurich, 8050 Zurich, Switzerland; \\ E-Mails: I.udris@ikmz.uzh.ch (L.U.),m.eisenegger@ikmz.uzh.ch (M.E.), andrea.haeuptli@uzh.ch (A.H.) \\ 2 Research Center for the Public Sphere and Society, University of Zurich, 8050 Zurich, Switzerland; \\ E-Mails: daniel.vogler@foeg.uzh.ch (D.V.), joerg.schneider@foeg.uzh.ch (J.S.) \\ * Corresponding author
}

Submitted: 14 April 2020 | Accepted: 10 July 2020 | Published: 24 August 2020

\begin{abstract}
In this article, we analyse how various macro- and meso-level factors influence news media's provision of hard news, an important element of media quality. The research draws on a content analysis of more than 100,000 news items between 2015 and 2019 from 53 print, radio, TV, and online news outlets in Switzerland, a small state with three linguistically segmented media markets, each of which is partially influenced by a large neighbouring country (Germany, France, and Italy). The research design takes into account the multi-dimensional character of hard news and allows for analysis with explanatory factors on different levels: On the meso-level, ownership types complemented with media types, and on the macro-level language regions of different market size. Findings show large differences in the importance of hard news overall and these findings are consistent across the three dimensions of hard news (topic dimension, focus dimension, style dimension). Hard news orientation differs especially between private and public media, but also within privately held media outlets, and less so within public media, which points to a general quality culture embedded within public media organizations. Thus, rather than by language region and the according media market size or by ownership types, quality differences can be best explained by media types.
\end{abstract}

\section{Keywords}

content analysis; hard news; media ownership; media quality; media types; news; Switzerland

\section{Issue}

This article is part of the issue "Media Performance in Times of Media Change" edited by Melanie Magin (Norwegian University of Science and Technology, Norway) and Birgit Stark (Johannes Gutenberg University Mainz, Germany).

(C) 2020 by the authors; licensee Cogitatio (Lisbon, Portugal). This article is licensed under a Creative Commons Attribution 4.0 International License (CC BY).

\section{Introduction}

Amid the ongoing transformation in the media sector, a major concern is that economic constraints and the increasing competition for audience share will reduce the quality of news, leading to a 'tabloidization' or 'softening' of news (Magin \& Stark, 2015). However, rather than assuming a universal trend, scholars point to the evidence that media performance or media quality still largely varies across individual outlets and types of media (Van Aelst et al., 2017, p. 8). These differences in the supply of news are important for several reasons. First, in current media policy debates, there is a growing consensus that the media increasingly lack the resources to produce high-quality journalism and should, therefore, be financially supported. Of course, this also implies that financial support should only be made if media companies actually invest in the quality of reporting. While the ownership form of public service media already includes legal obligations to invest in quality journalism, private media companies, especially those needing to satisfy shareholders, are more likely to save costs and reduce quality. Second, quality differences among media outlets on the supply side can go hand in hand with or even aggravate 
differences in the demand for quality news. In an integrative public sphere, however, good media quality occurs in several types of media spread across societal segments and strata and is not restricted to very few elite media outlets. Which outlets actually offer good quality and why some outlets offer better quality than others are therefore increasingly relevant questions.

Our article considers the role of media ownership and media types for media quality, focusing on the multi-dimensional concept of 'hard news' (Reinemann, Stanyer, Scherr, \& Legnante, 2012) as one important indicator of media quality. Additionally, we devote our attention to macro-level factors by investigating a multilingual country with segmented media markets. We chose Switzerland, a typical case of the "central" model of media and politics according to Brüggemann, Engesser, Büchel, Humprecht, and Castro (2014). At the same time, Switzerland is a particularly interesting case for three reasons. First, Switzerland's media system is segmented along language regions, each of which is different in market size and partially shaped by the larger neighboring countries (Germany, France, and Italy). Second, Switzerland's media structures in the private press sector changed later but more rapidly than in neighboring countries (Udris \& Lucht, 2014). This includes the rapid success of traditional commercial tabloid and newer tabloidlike cost-free commuter newspapers both offline and online. In fact, according to survey data from 38 markets (Newman, Fletcher, Kalogeropoulos, \& Nielsen, 2019), Switzerland now is the only country where a cost-free commuter outlet is the dominant brand in the print and online sector. Third, despite this trend towards commercialization, Switzerland has a strong public service broadcaster. This is typical as small states tend to adopt a regulatory approach to counter commercial pressures (Puppis, 2009, pp. 10-11). In sum, the multilingual Swiss media system shows both homogenizing patterns, e.g., a widely used public service broadcaster and successful cost-free commercial newspapers operating in all three language regions, but also differentiation patterns accompanied by different opportunities in each of the three media markets.

The first goal of our article is to map this multilingual media system in the three language regions and check the commonalities and differences of media outlets in terms of their hard news orientation. The second goal of the article is to explain hard news orientation by systematically comparing ownership modes, media types, and language regions. We make use of a unique dataset, which includes multi-dimensional hard news measures for 53 different media outlets in three language regions in Switzerland based on a representative manual content analysis of more than 100,000 news items between 2015 and 2019.

\section{Hard News and the Quality of News Media}

Given the essential functions of news media in modern democracies, the quality of news has been an important field of research. At the same time, many scholars involved in the study of media quality "have outlined the conceptual difficulties of applying one standard of excellence to all news markets" (Jandura \& Friedrich, 2014, p. 368). Numerous lists and catalogues exist which differ in (the number of) quality criteria and their theoretical background (e.g., Rodríguez Hidalgo, Rivera-Rogel, \& Romero-Rodríguez, 2020; Schatz \& Schulz, 1992). Within this heterogeneous literature, the consensus is that media quality is best understood in relation to normative concepts of democracy (Strömbäck, 2005) and that media quality itself is a multi-dimensional concept (Maurer, 2017). For the purpose of this article, we do not discuss the debates about different normative concepts and how empirical findings would ideally be interpreted and contrasted in light of different models of democracy (e.g., liberal vs. participatory model) but rather focus on the issue of dimensions of media quality.

Apart from highly notable exceptions where different quality dimensions and their interplay are analyzed empirically in a systematic way (de Vreese, Claes H., Esser, \& Hopmann, 2017; Seethaler, 2015), most scholars empirically use more or less detailed and fine-grained analyses to focus on only one quality dimension or one quality concept such as diversity (Humprecht \& Esser, 2017), impartiality and balance (Cushion \& Lewis, 2017), or deliberation (Wessler \& Rinke, 2014). Among the studies focusing on one concept, the concept of 'hard news' has increasingly gained traction. It is rooted in wider debates about the 'tabloidization' or 'softening' of news in general, especially in political news coverage (Otto, Glogger, \& Boukes, 2017), and hard news itself is sometimes even taken as a synonym for media quality as in "quality hard news journalism" (Anderson, 2016). The concept of hard news has been conceptually specified by Reinemann et al. (2012) and tested in empirical studies by Magin and Stark (2015), and Reinemann, Stanyer, and Scherr (2017). In the model proposed by Reinemann et al. (2012, p. 232), hard news is distinguished from soft news along three dimensions: "(1) The subject matter covered (topic dimension), (2) the specific aspects of events or topics emphasized (focus dimension), and (3) the way events or topics are visually and verbally presented (style dimension)." For instance, a news item about political affairs (topic) which puts events into context (focus dimension) and presents them in a matter-of-fact, unemotional tone (style) would be on one end of the spectrum of hard news vs. soft news, while a news item about sports which simply recounts the events using emotional language would be on the other end. This multi-dimensional conceptualization of hard news has two advantages. First, it takes into account insights from the research on 'media logic' where the selection (topic dimension), the interpretation (focus dimension) and the portrayal (style dimension) of news are distinguished (e.g., Meyen, 2015). Second, and even more importantly, it addresses the relevance (through the topic and focus dimension) and deliberation (through the style dimension) in news media 
content and can thus be considered an important indicator of media quality overall.

\section{Hard News and Quality Explained}

When comparing media quality and hard news across outlets in various media sectors and channels, scholars usually find large variation. Seethaler (2015), for instance, observed that the shares of hard news topics ranged from around $40 \%$ on the website of the costfree newspaper Österreich to more than $90 \%$ in the subscription newspaper Der Standard. This begs the obvious question of how these striking differences can be explained. As Picard and van Weezel (2008, p. 29) observed, "good and poor performance can result under all forms." However, against this 'every organization is different' argument, scholars working with comparative studies and relying on multi-level models such as the "hierarchy of influences" model propagated by Reese and Shoemaker (2016) have repeatedly stressed the importance of meso- and macro-level factors to explain media content in general (cf. paragraph below): modes of ownership (meso), media types (falling between the mesoand macro-level), and the media system as such, which offers a certain market size, follows path-dependencies from general models of media and politics, and is embedded in specific communication cultures (macro-level).

In their theoretical discussion of new institutionalism and field theory, Benson, Neff, and Hessérus (2018, pp. 276-277) argue that the degree of hard news "public affairs coverage," one central indicator of media's "public service orientation," depends also on ownership of media outlets. The premise is that the three "broad modes of ownership" as a meso-level factor-political instrumentalism, economic instrumentalism, and public service orientation-affect journalistic practice and thus media content (quality reporting). A similar argument is made by Nielsen, who speaks of the "power," "profit," and the "the public" rationale when organizations operate media outlets (Nielsen, 2017). In the power rationale, media are operated as organs of influence by their owners similarly to political parties or religious organizations, who ultimately want to change the world. While the profit rationale means that the operation of a news outlet is-ceteris paribus-about making profit, the public rationale is about "politically mandated delivery of a service to the public" (Nielsen, 2017, p. 34). From this perspective, public service media as ideal types are considered to be in the best position to serve the public interest and offer the highest quality of reporting.

These three modes serve as ideal types and in practice, news media might follow more than one rationale at the same time or have a mode of ownership falling in between the three modes. This applies particularly to privately owned media organization operating in the profit rationale, whose degree of profit orientation can substantially differ. This is why the literature has suggested distinguishing between privately held media organizations and those which are traded on the stock market. Stock market-listed media organizations experience greater pressure from shareholders and are more highly profit-driven than other types of media organization (e.g., McMenamin, Flynn, O'Malley, \& Rafter, 2013; Picard, 2004). As a result, they are more likely to achieve higher profits by cutting newsroom budgets and reducing the amount and quality of news (Dunaway \& Lawrence, 2015). In sum, the literature suggests that public ownership more so than private ownership, and even more so than publicly traded stock-market ownership, should go hand in hand with higher-quality reporting, hence a higher hard news orientation.

Another strand of the literature argues that differences in news performance result primarily from specific media types (e.g., Karidi, 2018), i.e., groups of media outlets which share certain characteristics such as business and revenue models (e.g., reliance on advertising instead of subscription revenue), audience orientation (e.g., up-market vs. down-market newspapers), production schedules (e.g., daily or weekly outlets), and media channels (e.g., press, television, online). For instance, in their cross-country content analysis of political news, Reinemann et al. (2017, p. 147) concluded that "medium type explains the extent to which more hard news or less hard news is published," i.e., public TV and broadsheet newspapers offered more hard news than commercial TV or tabloids. Similarly, observing large differences in how media use soft news elements of human interest in election coverage, Strömbäck and Van Aelst (2010) find that media types matter and that scholars should systematically consider them as "structural antecedents" of news coverage. So far, media types (e.g., commercial vs. public service TV news) seem to trump mere channels (e.g., print vs. TV) as explanatory factors. Whether online channels, given their production logics, still differ from other channels and lead, for instance, to lower hard news orientation or whether there is homogenization between offline and online counterparts, is still an open question (e.g., Steiner, Magin, \& Stark, 2019).

Finally, literature, especially in the tradition of comparative studies, evidently argues for the importance of macro-level media system factors. At the media system level, smaller market size and the associated high production costs have been found to reduce media quality and provision of hard news (Reinemann et al., 2017). Usually, media system factors such as market size are tested by comparing different countries to better isolate them from non-media factors such as the political system (e.g., Kriesi, 2012). In this light, multilingual countries such as Belgium, Canada, or Switzerland might offer another alternative to examine media system factors. Segmented media markets within one country share the same political system and often also share the same media organizations (e.g., the same national public service broadcaster), thus allowing researchers to keep these additional macro-level factors constant and to focus on market size. This becomes especially interesting in multilin- 
gual countries where segmented media markets clearly differ in size, as in Switzerland, the case for our analysis. Switzerland has four language regions (including a very small one including only $0.5 \%$ of the population) and thus four official languages (German, French, Italian, and Rhaeto-Romanic). The language regions constitute more or less independent and segmented media markets. Most people in German-speaking Switzerland, for instance, only consume media outlets from Germanspeaking and never from French- or Italian-speaking Switzerland. Many Swiss citizens also use media from the neighboring countries, i.e., Germany, France, and Italy, while people in those countries rarely use Swiss media. This segmentation into three submarkets and the influence of the 'next door giants' further reduce the size of the already small media market within which Swiss media can operate. The market in German-speaking Switzerland consists of 5,2 million adults, with the markets in French-speaking Switzerland (1,8 million), and especially in Italian-speaking Switzerland (roughly 300,000) being even smaller. Given these differences in market size, one could expect higher media quality for outlets in German-speaking Switzerland, given that more resources are available (e.g., size of the audience translates into more public funding for the public broadcaster as well as providing more advertising and subscription revenue). At the same time, one could also expect greater variation among media types and within media types within the German-speaking market than in the smaller markets. With a higher number of competitors, product differentiation becomes more important, which is why quality (high or low) could be one of the distinguishing features of a media outlet. In this light, it is not surprising to see that Switzerland's media companies launched cost-free, tabloidized commuter newspapers initially in the largest language region and finally in the smallest language region. Overall, however, one could expect a higher hard news orientation in German-speaking Switzerland than in the other two language regions.

To sum up, differences in hard news orientation are also to be expected in the case of Switzerland. Regarding media ownership, public service media are expected to offer more hard news than semi-public, private and, above all, stock market traded companies (H1). Regarding media types, public radio, and public TV, as well as subscription newspapers, are expected to offer most hard news, and commercial newspapers are expected to offer the least $(\mathrm{H} 2)$. Furthermore, we explore whether online news media offer more or less hard news than their offline counterparts (RQ1). Regarding language regions, hard news orientation is expected to be highest in German-speaking Switzerland, the largest media market, and lowest in Italian-speaking Switzerland, the smallest media market $(\mathrm{H} 3)$.

In the following section, we describe the methods used to map and explain hard news orientation in Switzerland generally as well as within its three main language regions.

\section{Method}

The data in this article comes from a large content analysis of the daily output of 53 media outlets in Switzerland in all three language regions. By including newspapers, online news sites, radio and television newscasts, and news magazines, all relevant types of news media were considered. Below, we first sketch how the selected media outlets are categorized into our explanatory variables, i.e., ownership, media type, and language region (Section 4.1). We then give information on the dependent variable, i.e., hard news and its three dimensions (Section 4.2).

\subsection{Media outlets: Ownership, Media Types, and Language Regions}

The selection of media outlets (see Table 1 and the Supplementary File) was done to assure that those outlets with the highest reach of each media type were represented. For each outlet and each calendar year (cf. Section 4.2), we determined the ownership category, media type, and language region. For ownership, we determined the company which ultimately owned the media and classified those companies along with their basic ownership structure and mode of financing. Public ownership refers to the public service broadcaster SRG SSR, which receives a license fee of more than one billion Swiss Francs annually to offer radio, television, and online services. Private ownership applies to print and online media produced by privately-owned companies; the private company Tamedia (now TX Group), however, is publicly listed on the stock market; hence it is coded as stock. Finally, semi-public ownership applies to regional or local TV programs offered by private companies which have a license to offer regional news and the right to be broadcast by cable operators ('must carry' rule). They receive public funding, which can even make up more than half of a station's revenue, which is why we coded them as semi-public and not as private. The private regional broadcaster Telezüri, however, which does not receive any funding and does not operate with a license, was coded as private.

The categorization of media types was based on the distinction of media channels, audience orientation, and revenue models. In broadcasting, apart from local TV news, we examined news from the public broadcaster. In the press, there are mass-market oriented tabloid and tabloid-like cost-free newspapers, highly reliant on advertising, as well as subscription newspapers, which obviously generate a larger amount from subscriptions. Table 1 shows that media types from the print, television, and radio sector usually have online equivalents (marked with ON), with the exception of local TV stations, which often lack the resources to offer a fully-fledged up-todate news site beyond simply a collection of video clips.

Of course, there is some overlap between ownership and media type categories (cf. Supplementary File) 
Table 1. Media sample: Number of outlets and news items examined.

\begin{tabular}{|c|c|c|c|c|c|c|c|c|c|}
\hline & & & nan & & & & ian & & \\
\hline & & & $n$ & & $n$ & & $n$ & & $\mathrm{n}$ \\
\hline Ownership & Private & 16 & 33446 & 5 & 6957 & 2 & 5404 & 23 & 45807 \\
\hline & Public & 5 & 6933 & 3 & 4322 & 3 & 4730 & 11 & 15985 \\
\hline & Semi-public & 3 & 4876 & 1 & 691 & 1 & 1349 & 5 & 6916 \\
\hline & Stock & 7 & 17836 & 5 & 12612 & 2 & 2530 & 14 & 32978 \\
\hline Media type & COMM & 3 & 4998 & 1 & 2301 & 1 & 1216 & 5 & 8515 \\
\hline & COMM ON & 4 & 8099 & 2 & 5049 & 1 & 1314 & 7 & 14462 \\
\hline & LOCAL TV & 4 & 6593 & 1 & 691 & 1 & 1349 & 6 & 8633 \\
\hline & PUBLIC ON & 1 & 1305 & 1 & 1229 & 1 & 1605 & 3 & 4139 \\
\hline & PUBLIC RADIO & 2 & 3163 & 1 & 1339 & 1 & 1344 & 4 & 5846 \\
\hline & PUBLIC TV & 2 & 2465 & 1 & 1754 & 1 & 1781 & 4 & 6000 \\
\hline & SUB & 9 & 22809 & 4 & 7288 & 1 & 3929 & 14 & 34026 \\
\hline & SUB ON & 6 & 13659 & 3 & 4931 & 1 & 1475 & 10 & 20065 \\
\hline total & & 31 & 63091 & 14 & 24582 & 8 & 14013 & 53 & 101686 \\
\hline
\end{tabular}

Notes: Total $\mathrm{N}=101,686$ news items. The table shows the number of outlets and the number of content-analyzed news items ( $\mathrm{n}$ columns) in each category. Media types: Tabloid and cost-free commercial newspapers (COMM) and their websites (COMM ON); local TV stations (LOCAL TV); radio and TV news by the public service broadcaster (PUBLIC RADIO, PUBLIC TV) and its websites (PUBLIC ON); subscription newspapers (SUB) and their websites (SUB ON).

because media outlets have developed in the context of interdependent market-specific and legal structures. Public service media constitute both a distinct type of ownership and distinct media types (public radio, public television, and the online news sites by the public broadcaster). Similarly, there are no purely publicly funded newspapers. Still, for most ownership types, several media types can be found empirically. AZ Medien (now CH Media), for instance, not only produces regional subscription newspapers but also a commercial news site, one local TV station not funded by the public license fee, and local TV stations which are largely publicly funded (semi-public). Finally, the language region was operationalized on the outlet level with the straightforward indicator in which language region the media outlet was produced.

\subsection{Hard News Measures}

The coding measures the degree of hard news in Switzerland's news outlets based on the abovementioned criteria. We conducted a secondary analysis of existing data on media quality in multiple dimensions (Research Center for the Public Sphere and Society [fög]-University of Zurich, 2019). The data comes from a manual content analysis of 53 outlets, including a representative sample of all news items in a calendar year (artificial weeks) regardless of the section (e.g., business section) or geographical scope (e.g., foreign news). In order to guarantee representativeness, the number of artificial weeks varied across outlets, as each outlet has a different daily output. In total, 101,686 news items were analyzed. The coding was done by a team of trained human coders; intercoder reliability scores were calculated using Krippendorff's alpha, showing satisfyingly high values for the variables we selected (societal sphere: 0.94, societal level: 0.79 , thematic framing: 0.88 , communication style: 0.74; Research Center for the Public Sphere and Society [fög] -University of Zurich, 2019, p. 171).

For our operationalization, we took into account all three dimensions of hard news (cf. Table 2). Among the variables in the dataset, we selected those which matched (at least largely) the conceptualization of Reinemann et al. (2012).

As for the topic dimension, we coded the main topic, distinguishing between societal spheres. Our definition of a hard news topic is wider than that used by Reinemann et al. (2012), who mainly measure the political relevance. Since our sample includes news coverage about topics beyond politics, we rely on Curran, lyengar, Brink Lund, and Salovaara-Moring (2009, p. 9), who define hard news as reports about politics, public administration, the economy, and arts and culture (which also includes media, science, technology, religion and related topics), while soft news consists of reports about celebrities, human interest, sport, and other entertainmentcentered stories. Only one main topic, thus one societal sphere, could be coded per news item.

On the focus dimension, we used two indicators. The first provides information about societal relevance. It was operationalized as news items focusing mainly on the macro-level (e.g., society or large parts of society), not the meso- (organizations) or the micro-level (individual actors). Only one level could be coded per news item. The second indicator addresses the difference between thematic and episodic framing (lyengar, 1991) and was measured with a binary variable. In the focus dimension, a hard news orientation thus means a higher importance 
Table 2. Operationalization of hard news.

\begin{tabular}{lll}
\hline Hard news dimension & Variables & Calculation \\
\hline Topic dimension & Societal sphere & \% of articles coded as 'politics, economy, or arts \& culture' \\
Focus dimension & $\begin{array}{l}\text { Societal level } \\
\text { Thematic vs. episodic } \\
\text { framing }\end{array}$ & $\begin{array}{l}\text { \% of articles coded as 'macro' } \\
\text { Focus dimension (total) }\end{array}$ \\
Style dimension & Communication style coded as 'thematic' & \% of articles coded as 'cognitive-rationalistic' \\
Hard news measure (total) & & (topic dimension + focus dimension (total) + style dimension) $/ 3$ \\
\hline
\end{tabular}

of news items focusing on the macro level and with a thematic framing.

In the style dimension, a binary variable distinguishing between a cognitive-rationalistic and a moralisticemotional communication style was used to take into account the dominant style of argumentation. We used the share of news items with a 'cognitive-rationalistic' communication style as an indicator of hard news.

Finally, as proposed by Reinemann et al. (2017), we combined the dimensions into an overall hard news measure, with each dimension having the same weight. This is why we also calculated the arithmetic mean between the two indicators in the focus dimension. As for the overall measure, no further transformations were necessary, as each indicator was of the same data type (i.e., share of news items within a category).

For the forthcoming analysis, we used the hard news measures per media outlet from each calendar year $(2015,2016,2017,2018,2019)$ as units of analysis also to account for possible variation of an outlet in the temporal dimension. The total number of cases (i.e., hard news measures of all outlets in all calendar years) was 258 instead of 265 because, for five media outlets, data was available for only three or four calendar years. These yearly hard news measures were used to calculate average measures for each category and to calculate the variation within each category (standard deviation).

\section{Results}

In this section, we first show descriptive statistics on hard news measures across ownership types, media types, and language regions before we turn to the regression model.

Table 3 makes it clear that public ownership is related to a higher hard news orientation, significantly and consistently across language regions, confirming $\mathrm{H} 1$. Contrary to our expectations, stock-market traded companies do not always offer less hard news compared to (other) private media companies; the provision of hard news is notably lower in French- and Italian-speaking Switzerland but not in German-speaking Switzerland. Furthermore, outlets of stock market traded companies overall have values rather similar to semi-public outlets. Thus, $\mathrm{H} 1$ is only partially supported.

One reason why three of the four ownership modes do not differ very much overall in terms of hard news orientation is that these three ownership modes consist of outlets with very heterogeneous hard news measures. Hence, variation within ownership modes clearly differs, as the standard deviation measures attest. Variation is relatively high within the semi-public mode (most of the examined local TV stations), even though our sample consists of only 5 outlets (SD 6.1\%), as well as being high within the stock market mode (15 outlets; SD 6.4\%),

Table 3. Average hard news measures by ownership type and language region.

\begin{tabular}{|c|c|c|c|c|c|c|c|c|c|}
\hline & \multicolumn{2}{|c|}{ German (X) } & \multicolumn{2}{|c|}{ French $(\mathrm{Y})$} & \multicolumn{2}{|c|}{ Italian (Z) } & \multicolumn{3}{|c|}{ Total } \\
\hline Private $\left({ }^{A}\right)$ & $49.7 \%$ & B & $58.0 \%$ & $B, D$ & $55.6 \%$ & $B, D$ & $52.0 \%$ & B & $11.7 \%$ \\
\hline Public (B) & $71.2 \%$ & $A, C, D$ & $68.8 \%$ & $A, D$ & $66.4 \%$ & A, D & $69.3 \%$ & $A, C, D$ & $4.2 \%$ \\
\hline Semi-public $\left({ }^{C}\right)$ & $50.6 \%$ & B & $59.9 \%$ & & $60.4 \%$ & $\mathrm{D}$ & $54.5 \%$ & B & $6.1 \%$ \\
\hline Stock $\left({ }^{D}\right)$ & $52.5 \%$ & B & $49.5 \%$ & $A, B, D$ & $47.3 \%$ & $A, B, D$ & $50.7 \%$ & B & $6.4 \%$ \\
\hline All & $54.1 \%$ & & $57.4 \%$ & & $58.2 \%$ & & $55.6 \%$ & & $11.3 \%$ \\
\hline
\end{tabular}

Notes: Total $\mathrm{N}=101,686$ news items in 258 units of analysis (measure per year and outlet). The table shows average hard news measures for each category in the three regions as well as the standard deviation for each of them. Means with letters are significantly higher than the comparison category at the $p<0.001$ level. 
and yet even higher within the private ownership mode (25 outlets; SD 11.7\%). To illustrate: In private companies, measures widely ranged from $28.7 \%$ (Blick am Abend in 2015 ) to $69.4 \%$ (NZZ in 2019). Compared to that, variation within the public ownership mode is quite low (11 outlets; SD 4.2\%).

Turning our attention to media types in Table 4, we observe differences which are clearer than those found for ownership modes. Hard news orientation is significantly higher not only in public media types (radio, television, partially also online) compared to most media types but also in subscription newspapers (and their online news sites) compared to commercial newspapers (and their online news sites), with local TV falling in between. $\mathrm{H} 2$ is supported. Thus, the Swiss media system is clearly stratified in terms of quality among media types. As for $\mathrm{RQ1}$, online media types do not offer less hard news than offline media counterparts.

While media types clearly differ from each other, it is also important to take into account the variation within media types. Again, variation differs; it is much lower within the public media types (radio, TV, online) but especially high within commercial newspapers and local TV news. Thus, the data points to the importance of media types as antecedents of hard news orientation but also to organization-specific factors. The case of local TV is instructive. The six selected news outlets widely range from $44.5 \%$ (Tele $M 1$ in 2016) to $66.8 \%$ (Léman Bleu in 2015). All these local news outlets, which operate in rather small regional markets, have relatively small budgets of roughly 5 to 10 million Swiss Francs per year and all but one (Telezüri) have a license and the same legal obligations to produce local news. These considerable differences are probably the strongest argument in our data that hard news orientation depends also on the editorial mission or 'quality strategy' of a specific media company.

Finally, there are hardly any differences in hard news orientation associated with the language regions. Contrary to H3, hard news orientation is not highest in German-speaking Switzerland but in the smallest language region-the region with the smallest media market. In line with our expectation, however, we find smaller variation especially in Italian-speaking Switzerland, possibly a result of a homogenization process. Differences among media outlets and types are not as marked (standard deviation: $8.4 \%$, not displayed) as in French-speaking Switzerland (standard deviation: 9.9\%) and the largest media market in German-speaking Switzerland (standard deviation: 12.3\%). The Germanspeaking media market features both several subscription newspapers which carry a lot of hard news and several commercial newspapers with very little hard news: most likely the result of there being greater opportunities for product differentiation given the bigger market size.

To better test the importance of the explanatory factors and to check possible differences among the three dimensions of hard news, we used a regression model. The model also controls for the calendar year, allowing one to see possible changes over time. The model in Table 5 supports the finding described above that media types best explain the differences in media's overall hard news orientation. Compared to media types, ownership (measured with a binary variable contrasting public and semi-public ownership from private and stock ownership) has hardly any impact. Language regions have a relatively small effect as well. Hardly any effects can be

Table 4. Average quality scores by media type and language region.

\begin{tabular}{|c|c|c|c|c|c|c|c|c|c|}
\hline & \multicolumn{2}{|c|}{ German (X) } & \multicolumn{2}{|c|}{ French $(\mathrm{Y})$} & \multicolumn{2}{|c|}{ Italian (Z) } & \multicolumn{3}{|c|}{ Total } \\
\hline $\operatorname{COMM}\left({ }^{\mathrm{A}}\right)$ & $35.2 \%$ & $C, D, E, F, G, H$ & $45.4 \%$ & $D, E, F$ & $46.1 \%$ & $C, D, E, F, G, H$ & $39.0 \%$ & $C, D, E, F, G, H$ & $8.7 \%$ \\
\hline COMM ON $\left({ }^{\mathrm{B}}\right)$ & $37.5 \%$ & $C, D, E, F, G, H$ & $44.8 \%$ & $C, D, E, F, G, H$ & $48.5 \%$ & $C, D, E, F, G$ & $41.8 \%$ & $C, D, E, F, G, H$ & $6.0 \%$ \\
\hline LOCAL TV $\left({ }^{C}\right)$ & $50.0 \%$ & $A, B, D, E, F, G, H$ & $59.9 \%$ & B & $60.4 \%$ & $A, B, E, F$ & $53.4 \%$ & $A, B, D, E, F$ & $6.1 \%$ \\
\hline PUBLIC ON $\left({ }^{D}\right)$ & $66.5 \%$ & $A, B, C$ & $65.4 \%$ & $A, B$ & $61.0 \%$ & $A, B, E, F, H$ & $64.3 \%$ & $A, B, C, H$ & $2.8 \%$ \\
\hline PUBLIC RADIO ( $\left.{ }^{\mathrm{E}}\right)$ & $73.2 \%$ & $A, B, C, G, H$ & $72.1 \%$ & $A, B, G, H$ & $70.1 \%$ & $A, B, C, D, G, H$ & $72.1 \%$ & $A, B, C, G, H$ & $2.2 \%$ \\
\hline PUBLIC TV $\left({ }^{F}\right)$ & $71.7 \%$ & $A, B, C, G, H$ & $69.0 \%$ & $A, B$ & $68.2 \%$ & $A, B, C, D, G, H$ & $70.1 \%$ & $A, B, C, G, H$ & $3.2 \%$ \\
\hline $\operatorname{SUB}\left({ }^{G}\right)$ & $57.4 \%$ & $A, B, C, E, F$ & $58.3 \%$ & $B, E$ & $57.5 \%$ & $A, B, E, F$ & $57.7 \%$ & $A, B, E, F$ & $5.4 \%$ \\
\hline SUB ON $\left({ }^{\mathrm{H}}\right)$ & $57.3 \%$ & $A, B, C, E, F$ & $56.4 \%$ & $B, E$ & $53.7 \%$ & $A, D, E, F$ & $56.7 \%$ & $A, B, D, E, F$ & $5.5 \%$ \\
\hline All & $54.1 \%$ & & $57.4 \%$ & & $58.2 \%$ & & $55.6 \%$ & & $11.3 \%$ \\
\hline
\end{tabular}

Notes: Total $\mathrm{N}=101.686$ news items in 258 units of analysis (measure per year and outlet). The table shows average hard news measures for each category in the three regions as well as the standard deviation for all outlets of each category. Means with letters are significantly higher than the comparison category at the $p<0.001$ level. Media types: Tabloid and cost-free commercial newspapers (COMM) and their websites (COMM ON); local TV stations (LOCAL TV); radio and TV news by the public service broadcaster (PUBLIC RADIO, PUBLIC TV) and its websites (PUBLIC ON); subscription newspapers (SUB) and their websites (SUB ON). 
Table 5. Model predicting (dimensions of) hard news orientation.

\begin{tabular}{|c|c|c|c|c|c|c|c|c|}
\hline \multirow[b]{2}{*}{ Predictors } & \multicolumn{2}{|c|}{ Hard news } & \multicolumn{2}{|c|}{ Topic dimension } & \multicolumn{2}{|c|}{ Focus dimension } & \multicolumn{2}{|c|}{ Style dimension } \\
\hline & Estimates & Std. Error & Estimates & Std. Error & Estimates & Std. Error & Estimates & Std. Error \\
\hline (Intercept) & $39.19^{* * *}$ & 1.27 & $37.35^{* * *}$ & 1.92 & $10.90^{* * *}$ & 1.25 & $69.32^{* * *}$ & 1.72 \\
\hline year_ordinal & -0.37 & 0.24 & $-0.75^{*}$ & 0.37 & $-0.48^{*}$ & 0.24 & 0.13 & 0.33 \\
\hline $\begin{array}{l}\text { language region } \\
\text { [French] }\end{array}$ & $2.43^{* *}$ & 0.81 & $4.44^{* * *}$ & 1.22 & $-2.68^{* * *}$ & 0.79 & $5.51^{* * *}$ & 1.10 \\
\hline $\begin{array}{l}\text { language region } \\
\text { [Italian] }\end{array}$ & $2.27^{*}$ & 1.00 & 1.39 & 1.51 & $-2.28^{*}$ & 0.98 & $7.69^{* * *}$ & 1.35 \\
\hline $\begin{array}{l}\text { media type } \\
\text { [COMM ON] }\end{array}$ & 2.52 & 1.44 & 1.57 & 2.17 & $3.02^{*}$ & 1.41 & 2.98 & 1.95 \\
\hline $\begin{array}{l}\text { media type } \\
\text { [LOCAL TV] }\end{array}$ & $9.86^{* * *}$ & 2.66 & $9.82^{*}$ & 4.02 & 1.95 & 2.61 & $17.82^{* * *}$ & 3.61 \\
\hline $\begin{array}{l}\text { media type } \\
\text { [PUBLIC ON] }\end{array}$ & $19.07^{* * *}$ & 3.19 & $28.12^{* * *}$ & 4.82 & $9.79^{* *}$ & 3.13 & $19.31^{* * *}$ & 4.33 \\
\hline $\begin{array}{l}\text { media type } \\
\text { [PUBLIC RADIO] }\end{array}$ & $27.29^{* * *}$ & 3.12 & $38.94^{* * *}$ & 4.71 & $20.79^{* * *}$ & 3.06 & $22.14^{* * *}$ & 4.23 \\
\hline $\begin{array}{l}\text { media type } \\
\text { [PUBLIC TV] }\end{array}$ & $25.31^{* * *}$ & 3.12 & $33.29^{* * *}$ & 4.71 & $22.46^{* * *}$ & 3.06 & $20.19^{* * *}$ & 4.23 \\
\hline media type [SUB] & $18.77^{* * *}$ & 1.24 & $22.69^{* * *}$ & 1.87 & $10.86^{* * *}$ & 1.22 & $22.75^{* * *}$ & 1.68 \\
\hline media type [SUB ON] & $17.63^{* * *}$ & 1.29 & $19.51^{* * *}$ & 1.95 & $13.15^{* * *}$ & 1.27 & $20.23^{* * *}$ & 1.75 \\
\hline ownership & $5.58^{*}$ & 2.69 & 7.10 & 4.06 & $5.80^{*}$ & 2.64 & 3.84 & 3.64 \\
\hline$R^{2} / R^{2}$ adjusted & 0.776 & 0.766 & 0.748 & 0.737 & 0.710 & 0.697 & $0.631 /$ & .615 \\
\hline
\end{tabular}

Notes: ${ }^{*} \mathrm{p}<0.05, * * \mathrm{p}<0.01, * * * \mathrm{p}<0.001$. Total $\mathrm{N}=101,686$ news items in 258 units of analysis (measure per year and outlet). For media types, the reference category is commercial newspapers (COMM); for language regions, the reference category is Germanspeaking Switzerland. Media types: Tabloid and cost-free commercial newspapers (COMM) and their websites (COMM ON); local TV stations (LOCAL TV); radio and TV news by the public service broadcaster (PUBLIC RADIO, PUBLIC TV) and its websites (PUBLIC ON); subscription newspapers (SUB) and their websites (SUB ON).

observed over time (year), which means there is no trend towards more or less hard news in Swiss media outlets between 2015 and 2019.

When we break down the hard news concept into its three dimensions, these (non-)effects basically stay the same as for the overall measure. This underlines the fact that all three dimensions are empirically part of the same overall construct. Slight deviations from this pattern can be found on the level of language regions and ownership. First, in the two smaller media markets, there is more hard news in the style dimension and (partially) in the topic dimension but not in the focus dimension. With much caution, this could be interpreted as an effect of the smaller market size, where fewer resources lead to a higher reliance on news agency reports, especially for hard news topics. The measures then might reflect news agencies' typical way of reporting (i.e., offering basic news instead of news analyses with thematic framing, written in a cognitive-rationalistic style). Second, the (small) effect of ownership is visible only in the focus dimension; non-private ownership, especially fully public ownership, is related to more thematic framing. This is one indication that stable funding makes the planning of news easier and leads to an organizational culture in which background reporting plays an important role. However, both interpretations would need to be tested with additional data and additional methods.

\section{Conclusions}

Based on a multi-dimensional operationalization of hard news (Reinemann et al., 2012), a central indicator of the overall quality of media, our study of 53 news outlets in Switzerland has revealed that hard news orientation crucially differs among individual outlets and especially among types of media. This result of a stratified media system serves as a reminder that any study on media quality in a given system needs to carefully select and justify a representative sample of outlets. As well as mapping media quality, our goal was to explain it. The factors examined, i.e., language regions and media markets on the macro level, types of ownership on the meso- 
level, and media types (falling between the meso- and the macro-level), turned out to be not equally important.

Ownership of media only had a limited effect. Against theoretical expectations, outlets of stock market traded companies did not perform worse than outlets from non-listed companies. However, public service media were found to substantially offer more hard news compared to other ownership forms, supporting previous research (e.g., Reinemann et al., 2017). Public service media across the three language regions performed quite similarly, indicating their "homogenization logic" described by Benson et al. (2018). Although its outlets are produced by three different operating units - Schweizer Radio und Fernsehen (SRF) in Germanspeaking Switzerland, Radio Télévision Suisse (RTS) in French-speaking Switzerland, and Radiotelevisione svizzera (RSI) in Italian-speaking Switzerland-the overall umbrella organization SRG SSR and the according legal mandate seem to have contributed to an overall editorial mission which promotes quality. This is an important finding given that public service media are especially accountable and responsible for producing quality journalism. Compared to ownership, media types as explanatory factor turned out to be much more closely related to the amount of hard news measured and thus explained the differences better. Media types also explain the differences better than mere channels; in our data, websites of news outlets did not differ much from their counterparts in the radio, TV, or print sector. We therefore strongly underline the plea by Strömbäck and Van Aelst (2010) that media types should be systematically considered as structural antecedents of news coverage in content analyses.

Finally, the language regions did not differ significantly in terms of hard news provision, nor did we see a negative impact of small market size on hard news orientation. However, the size of the market turned out to explain the degree of variation within language regions, with the largest market showing the highest variation and product differentiation and the smallest market showing the lowest. In light of the similar results across language regions, we do not presuppose that other, more cultural differences on the macro-level might are unimportant when explaining how much hard news is offered. However, theoretical expectations are ambivalent; while comparative research on 'communication cultures' shows fewer "popularization techniques" and thus higher quality in German-speaking countries (including German-speaking Switzerland; Umbricht \& Esser, 2016), comparative research on journalists' role conceptions suggests the opposite by finding less audience orientation and thus supposedly more hard news in the Francophone countries (including French-speaking Switzerland; Bonin et al., 2017). More research is needed to link specific cultural factors to specific dimensions and indicators of media quality. Apart from our explanatory factors, our data still showed considerable variation within media types and language regions and especially within ownership modes. To a certain extent, quality in general, and hard news orientation in particular, is contingent upon the structures and strategies of specific organizations and their news outlets. This finding has two implications. First, scholars are encouraged to look for other structural factors which explain quality; second, if quality also depends more on 'soft' or organizationspecific factors which can hardly be measured, any media regulation which includes funding (requiring quality journalism) needs to focus on media content as the actual output.

Our study also comes with limitations. First, the focus on Switzerland limits the generalizability of the results, although Switzerland can be considered a good representative of the central model. In future research, news in Switzerland's segmented media system could be compared with other multilingual systems, ideally, Belgium or Canada, or one Swiss language region could be compared with neighboring countries. The collaborative project "Media Performance and Democracy" (https:// en.mediaperformance.uni-mainz.de) is currently working on explaining media quality in Austria, Germany, and German-speaking Switzerland based on a wide set of quality indicators, including hard news. Second, although we tested several possible factors to explain certain aspects of media quality, our method relying on content analysis did not allow us to flesh out the exact mechanisms. In order to find out exactly how public ownership, for instance, affects media quality, other methods such as newsroom observations are needed. Third, we measured each outlet separately and could not take into account the fact that an outlet's quality might stem mainly from resources jointly shared with other outlets. In fact, to save costs, three large Swiss media companies have been implementing centralized newsrooms above the outlet level, where news items are shared among different outlets, reducing diversity at the system level. Given that this problem is spreading also in countries like Germany (e.g., Funke) and the US (e.g., Gannett), scholars should turn their attention to this type of "media content concentration" (Vogler, Udris, \& Eisenegger, 2020). Fourth, due to the increasing importance of thirdparty platforms, it would be necessary to examine media types including third-party platforms (e.g., outlets' Twitter accounts, Facebook pages etc.) to check to what extent outlets possibly adapt to the platforms' logics and change their hard news orientation (Häuptli, Schwaiger, \& Eisenegger, 2020; Steiner et al., 2019).

Despite these limitations, our article presents a comprehensive mapping of media quality based on theoretically derived indicators of hard news, which could be used and refined in subsequent studies. Examining a large and representative sample of outlets across different channels and examining the typical output of outlets from all different sections, our article contributes to the ever-burning question of which structural factors can and which cannot explain the quality of news coverage. 


\section{Acknowledgments}

This work was supported by the Kurt Imhof Stiftung für Medienqualität.

\section{Conflict of Interests}

The authors declare no conflict of interests.

\section{Supplementary Material}

Supplementary material for this article is available online in the format provided by the authors (unedited).

\section{References}

Anderson, P. J. (2016). Defining and measuring quality news journalism. In P. J. Anderson, G. Ogola \& M. Williams (Eds.), The future of quality news journalism: A cross-continental analysis (pp. 7-34). New York, NY, and London: Routledge.

Benson, R., Neff, T., \& Hessérus, M. (2018). Media ownership and public service news: How strong are institutional logics? The International Journal of Press/Politics, 23(3), 275-298. https://doi.org/ $10.1177 / 1940161218782740$

Bonin, G., Dingerkus, F., Dubied, A., Mertens, S., Rollwagen, H., Sacco, V., . . . Wyss, V. (2017). Quelle Différence? Language, culture and nationality as influences on francophone journalists' identity. Journalism Studies, 18(5), 536-554. https://doi.org/ 10.1080/1461670X.2016.1272065

Brüggemann, M., Engesser, S., Büchel, F., Humprecht, E., \& Castro, L. (2014). Hallin and Mancini revisited: Four empirical types of Western media systems. Journal of Communication, 64(6), 1037-1065. https://doi.org/ 10.1111/jcom.12127

Curran, J., Iyengar, S., Brink Lund, A., \& SalovaaraMoring, I. (2009). Media system, public knowledge and democracy: A comparative study. European Journal of Communication, 24(1), 5-26.

Cushion, S., \& Lewis, J. (2017). Impartiality, statistical tit-for-tats and the construction of balance: UK television news reporting of the 2016 EU referendum campaign. European Journal of Communication, 32(3), 208-223. https://doi.org/10.1177/ 0267323117695736

de Vreese, C. H., Esser, F., \& Hopmann, D. N. (Eds.). (2017). Comparing political journalism. London and New York, NY: Routledge.

Dunaway, J., \& Lawrence, R. G. (2015). What predicts the game frame? Media ownership, electoral context, and campaign news. Political Communication, 32(1), 43-60. https://doi.org/10.1080/ 10584609.2014.880975

Häuptli, A., Schwaiger, L., \& Eisenegger, M. (2020). The effect of democratic media quality on user engagement on social media: An analysis of the con- tents of five Swiss news media outlets on Facebook. In V. Gehrau, A. Waldherr, \& A. Scholl (Eds.), Integration durch Kommunikation: Jahrbuch der Publizistik-und Kommunikationswissenschaft 2019 [Integration through communication: Yearbook of the German communication association 2019] (pp. 99-108). Münster: Deutsche Gesellschaft für Publizistik- und Kommunikationswissenschaft e.V. https://doi.org/10.21241/SSOAR.66880

Humprecht, E., \& Esser, F. (2017). Diversity in online news. Journalism Studies, 61(4), 1-23. https://doi. org/10.1080/1461670X.2017.1308229

lyengar, S. (1991). Is anyone responsible? How television frames political issues. Chicago, IL: University of Chicago Press. https://doi.org/10.7208/chicago/ 9780226388533.001.0001

Jandura, O., \& Friedrich, K. (2014). The quality of political media coverage. In C. Reinemann (Ed.), Handbooks of communication science: Vol. 18. Political Communication (pp. 351-376). Berlin: de Gruyter Mouton.

Karidi, M. (2018). News media logic on the move? Journalism Studies, 19(9), 1237-1256. https://doi.org/ 10.1080/1461670X.2016.1266281

Kriesi, H. (2012). Personalization of national election campaigns. Party Politics, 18(6), 825-844.

Magin, M., \& Stark, B. (2015). Explaining national differences of tabloidisation between Germany and Austria. Journalism Studies, 16(4), 577-595. https://doi. org/10.1080/1461670X.2014.921398

Maurer, T. (2017). Quality. In P. Rössler, C. A. Hoffner, \& L. Zoonen (Eds.), The international encyclopedia of media effects (Vol. 30, pp. 1-8). Hoboken, NJ: Wiley. https://doi.org/10.1002/9781118783764. wbieme0189

McMenamin, I., Flynn, R., O’Malley, E., \& Rafter, K. (2013). Commercialism and election framing. The International Journal of Press/Politics, 18(2), 167-187. https://doi.org/10.1177/1940161212468031

Meyen, M. (2015). Aufmerksamkeit, Aufmerksamkeit, Aufmerksamkeit: Eine qualitative Inhaltsanalyse zur Handlungslogik der Massenmedien [Attention, attention, attention: $A$ qualitative content analysis of the mass media logic]. Publizistik, 60(1), 21-39. https:// doi.org/10.1007/s11616-014-0219-z

Newman, N., Fletcher, R., Kalogeropoulos, A., \& Nielsen, R. K. (Eds.). (2019). Reuters Institute Digital News Report 2019. Oxford: Reuters Institute for the Study of Journalism.

Nielsen, R. K. (2017). Media capture in the digital age. In In the service of power: Media capture and the threat to democracy (pp. 33-42). Washington, DC: The National Endowment for Democracy.

Otto, L., Glogger, I., \& Boukes, M. (2017). The softening of journalistic political communication: A comprehensive framework model of sensationalism, soft news, infotainment, and tabloidization. Communication Theory, 27(2), 136-155. https://doi.org/ 10.1111/comt.12102 
Picard, R. G. (2004). Commercialism and newspaper quality. Newspaper Research Journal, 25(1), 54-65.

Picard, R. G., \& van Weezel, A. (2008). Capital and control: consequences of different forms of newspaper ownership. International Journal on Media Management, 10(1), 22-31. https://doi.org/ $10.1080 / 14241270701820473$

Puppis, M. (2009). Media regulation in small states. International Communication Gazette, 71(1/2), 7-17. https://doi.org/10.1177/1748048508097927

Reese, S. D., \& Shoemaker, P. J. (2016). A media sociology for the networked public sphere: The hierarchy of influences model. Mass Communication and Society, 19(4), 389-410. https://doi.org/10.1080/15205436. 2016.1174268

Reinemann, C., Stanyer, J., \& Scherr, S. (2017). Hard and soft news. In C. H. de Vreese, F. Esser, \& D. N. Hopmann (Eds.), Comparing political journalism (pp. 131-149). London and New York, NY: Routledge.

Reinemann, C., Stanyer, J., Scherr, S., \& Legnante, G. (2012). Hard and soft news: A review of concepts, operationalizations and key findings. Journalism, 13(2), 221-239. https://doi.org/10.1177/ 1464884911427803

Research Center for the Public Sphere and Society (fög)University of Zurich. (Ed.). (2019). Jahrbuch Qualität der Medien 2019: Schweiz-Suisse-Svizzera [Yearbook Quality of the Media: Switzerland]. Basel: Schwabe.

Rodríguez Hidalgo, C., Rivera-Rogel, D., \& RomeroRodríguez, L. M. (2020). Information quality in Latin American digital native media: Analysis based on structured dimensions and indicators. Media and Communication, 8(2), 135-145. https://doi.org/ 10.17645/mac.v8i2.2657

Schatz, H., \& Schulz, W. (1992). Qualität von Fernsehprogrammen: Kriterien und Methoden zur Beurteilung von Programmqualität im dualen Fernsehsystem [Quality of television programs: Criteria and methods for evaluating program quality in the dual television system]. Media Perspektiven, 11, 690-712.

Seethaler, J. (2015). Qualität des tagesaktuellen Infor- mationsangebots in den österreichischen Medien: Eine crossmediale Untersuchung [Quality of the daily information supply in Austrian Media: A crossmedia analysis]. Vienna: Rundfunk und Telekom Regulierungs-GmbH.

Steiner, M., Magin, M., \& Stark, B. (2019). Uneasy bedfellows: Comparing the diversity of German public service news on television and on Facebook. Digital Journalism, 7(1), 100-123. https://doi.org/10.1088/ 0031-8949/79/01/015001

Strömbäck, J. (2005). In search of a standard: Four models of democracy and their normative implications for journalism. Journalism Studies, 6(3), 331-345.

Strömbäck, J., \& Van Aelst, P. (2010). Exploring some antecedents of the media's framing of election news: A comparison of Swedish and Belgian election news. The International Journal of Press/Politics, 15(1), 41-59.

Udris, L., \& Lucht, J. (2014). Mediatization at the structural level: independence from politics, dependence on the market. In F. Esser \& J. Strömbäck (Eds.), Mediatization of politics: Understanding the transformation of Western democracies (pp. 114-136). Basingstoke: Palgrave Macmillan.

Umbricht, A., \& Esser, F. (2016). The push to popularize politics. Journalism Studies, 17(1), 100-121. https:// doi.org/10.1080/1461670X.2014.963369

Van Aelst, P., Strömbäck, J., Aalberg, T., Esser, F., de Vreese, C. H., Matthes, J., . . . Stanyer, J. (2017). Political communication in a high-choice media environment: A challenge for democracy? Annals of the International Communication Association, 41(1), 3-27. https://doi.org/10.1080/23808985.2017.1288551

Vogler, D., Udris, L., \& Eisenegger, M. (2020). Measuring media content concentration at a large scale using automated text comparisons. Journalism Studies. Advance online publication. https://doi.org/ 10.1080/1461670X.2020.1761865

Wessler, H., \& Rinke, E. M. (2014). Deliberative performance of television news in three types of democracy: Insights from the United States, Germany, and Russia. Journal of Communication, 64(5), 827-851. https://doi.org/10.1111/jcom.12115

\section{About the Authors}

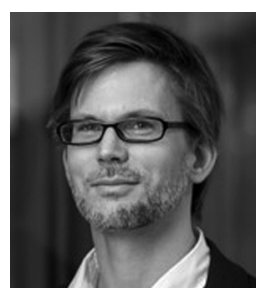

Linards Udris (DPhil) is a Senior Research Associate at the Department of Communication and Media Research at the University of Zurich and Deputy Director of Research at the Research Center for the Public Sphere and Society (fög) at the University of Zurich. His research interests lie in the quality of the media, political communication, especially during referendum campaigns, and social change.

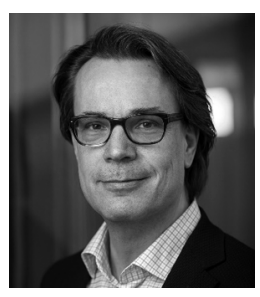

Mark Eisenegger (DPhil) is a Full Professor at the Department of Communication and Media Research at the University of Zurich and Director of the Research Center for the Public Sphere and Society (fög) at the University of Zurich. He is mainly interested in the digital transformation of the public sphere and its implications for the quality of the media and for organisational communication. 


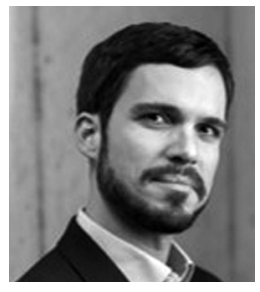

Daniel Vogler (DPhil) is Research Director of the Research Center for the Public Sphere and Society (fög) at the University of Zurich, and Research Associate at the Department of Communication and Media Research at the University of Zurich. His research focuses on public relations, especially in higher education, journalism, and online communication.

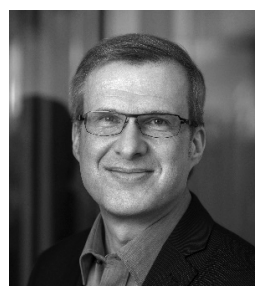

Jörg Schneider (MA) is an Associate Researcher at Research Center for the Public Sphere and Society (fög) at the University of Zurich, and owner of the empirical social research company js_studientanalysen. In his research, he focuses on media use, reputation research, and empirical methods such as surveys and data modelling.

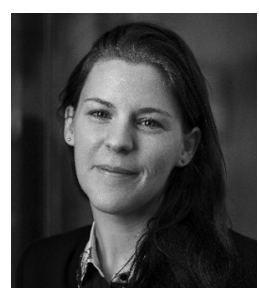

Andrea Häuptli is a PhD Student at the Department of Communication and Media Research (IKMZ) at the University of Zurich. She holds an MA degree in political science from ETH Zurich. Her research focuses on the quality of the media and on the transnationalisation of public spheres, especially in the Arab world. 